\title{
GESTÃO DEMOCRÁTICA NA ESCOLA: A PARTICIPAÇÃO NO CONTEXTO DA PRÁTICA DE UM PROGRAMA DE EDUCAÇÃO EM TEMPO INTEGRAL ${ }^{1}$
}

\author{
GESTIÓN DEMOCRÁTICA EN LA ESCUELA: LA PARTICIPACIÓN EN \\ EL CONTEXTO DE LA PRÁCTICA DE UN PROGRAMA DE EDUCACIÓN \\ INTEGRAL
} DEMOCRATIC SCHOOL MANAGEMENT: ENGAGEMENT IN THE
PRACTICE OF A COMPREHENSIVE EDUCATION PROGRAM CONTEXT

Janaína Specht da Silva MENEZES ${ }^{2}$ Rozineide Souza BRASIL ${ }^{3}$

RESUMO: Este trabalho tem como objetivo analisar a participação, sob a perspectiva da gestão democrática, a partir da presença do Programa Mais Educação (PME) na escola. Tendo por referência um estudo de caso realizado em uma escola da cidade de Belém, no Pará, Brasil, foram efetuadas observações e entrevistas, as quais foram submetidas à Análise de Conteúdos. Entre os resultados, destaca-se que o PME vem contribuindo para fortalecer práticas democráticas, na medida em que fomenta a reflexão e o desenvolvimento de atitudes e ações que evidenciam e estimulam a responsabilidade do conjunto da escola para com, por exemplo, a aprendizagem dos alunos. Todavia, a participação vem se dando de forma limitada, uma vez que se faz associar, especialmente, a alguns integrantes da administração escolar, apresentando, assim, como desafio a necessidade de envolver os diferentes segmentos educativos nas ações e decisões associadas não só ao PME, mas também a outros interesses da escola.

PALAVRAS-CHAVE: Políticas Públicas em Educação. Programa Mais Educação. Participação. Gestão democrática. Educação em Tempo Integral. Educação integral.

RESUMEN: Este trabajo tiene como objetivo analizar la participación, desde la perspectiva de la gestión democrática, a partir de la presencia del Programa "Mais Educação" (PME) en la escuela. Tomando como referencia a un estudio de caso realizado en una escuela de Belém, Pará, se realizaron observaciones y entrevistas, las cuales fueron sometidas al análisis de contenidos. Entre los resultados, se destaca que el "PME" viene contribuyendo a fortalecer prácticas democráticas, en la medida en que fomenta la reflexión y el desarrollo de actitudes y acciones que evidencian y

${ }^{1}$ Este artigo constitui-se produto de uma pesquisa realizada junto ao Programa de Pós-Graduação em Educação (PPGEdu) da Universidade Federal do Estado do Rio de Janeiro (Unirio), durante os anos de 2014 e 2015.

${ }^{2}$ Universidade Federal do Estado do Rio de Janeiro (Unirio), Rio de Janeiro - RJ - Brasil. Professora do Departamento de Didática e do Programa de Pós-Graduação em Educação da Unirio. E-mail: janainamenzes@hotmail.com.

${ }^{3}$ Rede Municipal de Ensino, Belém - PA - Brasil. Mestre em Educação pela Universidade Federal do Estado do Rio de Janeiro (Unirio). Administradora Escolar na Rede Municipal de Ensino, Belém - PA. Email: rozibrasil@yahoo.com.br. 
estimulan la responsabilidad del conjunto de la escuela con respeto, por ejemplo, al aprendizaje de los alumnos. Sin embargo, esta participación se viene dando de forma limitada, ya que se asocia especialmente a algunos integrantes de la administración escolar, presentando como desafio la necesidad de involucrar a los diferentes segmentos educativos en las acciones y decisiones asociadas no sólo al "PME", pero a otros intereses de la escuela.

PALABRAS CLAVE: Politicas públicas en educación. Programa "Mais Educação". Participación. Gestión democrática. Educación a tiempo integral. Educación integral.

ABSTRACT: This paper aims to analyze the engagement, from the perspective of democratic management, of the presence of the "Mais Educacao" Program (PME) project in schools. Based on a case study carried out in a school in Belem, State of Para, observations and interviews were made, which were submitted for content analysis. Among the results, it should be noted that the "PME" project has been contributing to strengthen democratic practices, as it fosters reflection and development of attitudes and actions that evidence and stimulate the responsibility of the whole school with, for example, the students' learning process. However, this engagement has taken place in a limited way, since it is especially associated to some members of the school administration, thus presenting the challenge of the need to involve different educational segments in the actions and decisions associated not only with the project, but with other interests of the school.

KEYWORDS: Public policies in education. "Mais Educacao" Program. Engagement. Democratic management. Full-time education. Comprehensive education.

\section{Introdução}

Criado em 2007, o Programa Mais Educação (PME) teve sua implantação restrita ao período de 2008 a 2016, ocasião em que, neste último ano, por ação do Governo Federal, sem a participação ou consulta aos diretamente envolvidos, foi substituído $^{4}$ pelo Programa Novo Mais Educação (PNME), o qual foi criado pela Portaria $n^{\circ}$ 1.144/2016 (BRASIL, 2016). A instituição do PNME ${ }^{5}$ surpreendeu estados e municípios e, em especial, as escolas que vinham desenvolvendo o PME no contexto de

${ }^{4}$ Entende-se, aqui, que a implantação do PNME rompeu com a instituição do PME. Se o PME apresentava, como diretriz, a implantação do tempo integral enquanto possível estratégia voltada para a conquista de uma educação integral, a qual estava disposta nos seus principais ordenamentos normativos (Portaria Interministerial $n^{\circ} 17 / 2007$ e Decreto $n^{\circ} 7.083 / 2010$ ), o PNME silencia a esse respeito na sua portaria de instituição (Portaria $n^{\circ} 1.144 / 2016$ ), estabelecendo, assim, uma ruptura com a perspectiva da educação integral disposta no programa que lhe antecedeu.

${ }^{5}$ Com nomenclatura semelhante, porém com propósitos diferentes ao programa que lhe antecedeu, o PNME não se constitui foco de análise do presente artigo.

RPGE - Revista on line de Política e Gestão Educacional, Araraquara, v. 22, n. esp.1, p. 137-158, mar., 2018. 
suas práticas ${ }^{6}$. Tal surpresa adveio, entre outros motivos, do fato de os documentos orientadores do PME, elaborados no âmbito do Governo Federal, apresentarem, de forma praticamente unânime, a importância da participação ${ }^{7}$ nos processos que envolviam a implementação do Programa, revelando, com a forma como foi instituído o PNME, certa incoerência entre os textos políticos e o contexto da prática corporificada por esse nível de governo.

Especificamente em relação à presença do PME na escola, observa-se que a responsabilidade para com o estímulo à participação se associava, prioritariamente, ao diretor, ao qual cabia o papel de "incentivar a participação, o compartilhamento de decisões e de informações com professores, funcionários, estudantes e suas famílias [...] promovendo a participação de todos os segmentos da escola nos processos de tomada de decisão" (BRASIL, 2011, p. 16). Para além da usual ideia de coordenação, a participação nos processos que abarcam a gestão na escola justifica-se, entre outros motivos, por se associar a valores que envolvem "a solidariedade, a reciprocidade e o compromisso" (PAZETO, 2000, p. 16), bem como por encerrar em si mesma "um potencial de crescimento da consciência crítica, da capacidade de tomar decisões e de adquirir poder" (BORDENAVE, 1994, p. 29-30). Sob essa perspectiva, a participação constitui-se um dos desafios das escolas que direcionam seus projetos políticopedagógicos para a formação integral de seus alunos.

Partindo desse contexto, neste trabalho, objetiva-se discutir a participação da comunidade escolar - participação esta considerada eixo fundante da gestão democrática (BRASIL, 2015) - nos processos que envolveram a implementação do PME em uma escola da rede municipal de Belém, no estado do Pará (PA), no Brasil.

A pesquisa, caracterizada como um estudo de caso - metodologia que abrange planejamento, técnicas de coleta de dados e análise destes (YIN, 2005) -, tomou por

\footnotetext{
${ }^{6}$ Embora não se apresente, aqui, como referencial teórico-metodológico, a utilização da expressão "contexto da prática" busca estabelecer uma referência à Abordagem do Ciclo de Políticas, concebida por Ball e Bowe (1992). Constituída, inicialmente, por três contextos - da influência, da produção do texto e da prática -, a Abordagem do Ciclo de Políticas foi, posteriormente, adicionada dos contextos dos resultados/efeitos e da estratégia política (MAINARDES, 2006). O contexto da prática abarca os esforços de transição do texto político para a prática, correspondendo, assim, ao contexto em que ocorrem as (re)interpretações e reações à política enquanto texto, e que se faz, portanto, acompanhar de consequências e desdobramentos (BALL; BOWE, 1992).

7 Apresentam-se, aqui, alguns excertos relativos à participação, os quais estão presentes nos dois principais ordenamentos do PME: "O Programa Mais Educação visa [...] fomentar a participação das famílias e comunidades nas atividades desenvolvidas" (BRASIL, 2007); "São objetivos do Programa Mais Educação: [...] favorecer a convivência entre professores, alunos e suas comunidades; [...] a integração entre escola e comunidade, para o desenvolvimento do projeto político-pedagógico de educação integral" (BRASIL, 2010).
} 
referência as informações decorrentes da realização de entrevistas ${ }^{8}$ semiestruturadas, realizadas com integrantes da comunidade escolar envolvidos com o PME. Os resultados, por sua vez, foram submetidos à Análise de Conteúdo, buscando atender as orientações de Bardin (1977).

Sendo assim, este artigo encontra-se segmentado em seis partes fundamentais, incluídas desta introdução. Na segunda seção, discute-se a educação em tempo integral, tendo por foco alguns de seus ordenamentos normativos. Na sequência, o estudo apresenta algumas reflexões acerca da gestão democrática na educação pública, para, a seguir, abarcar a discussão da participação nos contextos da gestão democrática e do tempo integral na educação. A quinta seção, que traz a análise de alguns dos principais resultados das entrevistas, está segmentada em três subseções, as quais tratam da participação de forma associada: (1) ao processo de adesão da escola ao PME, (2) à escolha dos macrocampos/oficinas, (3) aos critérios de seleção dos alunos e dos monitores. Por fim, nas considerações finais, são abordados alguns dos resultados do estudo realizado, também de modo a possibilitar delinear um perfil geral da participação no contexto da prática do PME em uma escola localizada na Região Norte do Brasil, região esta que, vale observar, se no ano de 2008 apresentava o menor percentual (2\%) de experiências de jornada escolar ampliada no país (BRASIL, 2009), já no ano de 2013, passou a contar com o PME em 441 (98\%) dos seus 450 municípios (BRASIL, 2013).

\section{Educação em tempo integral e o Programa Mais Educação}

Nas últimas décadas, em especial nos últimos anos, vimos assistindo a incursões das mídias, discursos políticos e programas de governos que referenciam à ampliação da jornada escolar como uma estratégia capaz de contribuir para o necessário avanço da qualidade da educação básica pública do país e, por conseguinte, da aprendizagem dos alunos.

A relevância da educação em tempo integral, no contexto nacional, adquiriu materialidade, entre outros fatores, a partir do crescente avanço da sua inserção no ordenamento normativo federal associado à educação. Tal avanço revela-se, especialmente, pelo alargamento da abrangência da sua oferta no contexto da educação

8 Foram entrevistadas a diretora, a coordenadora pedagógica e a coordenadora do PME na escola pesquisada, bem como professores regentes, monitores, alunos e pais, além do coordenador municipal do Programa. As entrevistas ocorreram nos meses de junho a outubro do ano de 2014.

RPGE - Revista on line de Política e Gestão Educacional, Araraquara, v. 22, n. esp.1, p. 137-158, mar., 2018. 
básica pública: se, no texto original da Lei de Diretrizes e Bases da Educação Nacional (LDBEN) (BRASIL, 1996), a ampliação da jornada escolar para o tempo integral estava associada exclusivamente ao ensino fundamental, no âmbito do Plano Nacional da Educação (PNE) 2001-2010 (BRASIL, 2001), passou a abarcar também a educação infantil, sendo que, a partir da aprovação do Fundo de Manutenção e Desenvolvimento da Educação Básica e de Valorização dos Profissionais da Educação (Fundeb) (BRASIL, 2006), atingiu todas as etapas da educação básica (MENEZES, 2009).

Foi durante a vigência do PNE 2001-2010 que o Programa Mais Educação foi instituído no país. Especificamente em relação ao PME, podemos afirmar que esse Programa emergiu em meio a um cenário em que as políticas públicas de educação vinham sendo focalizadas por meio da anunciação de uma visão sistêmica, à época presente nos planos e projetos do Ministério da Educação (MEC), a citar, no Plano de Desenvolvimento da Educação (PDE), o qual, tendo por alicerce o Plano de Ações Articuladas (PAR), contribuiu para que o PME, nos cinco primeiros anos de sua implantação, crescesse de tal forma a alcançar a maioria dos municípios brasileiros ${ }^{9}$.

O PME - que tinha por finalidade "contribuir para a melhoria da aprendizagem por meio da ampliação do tempo de permanência de crianças, adolescentes e jovens matriculados em escola pública, mediante oferta de educação básica em tempo integral" (BRASIL, 2010, Art. $1^{\circ}$ ) - pode ser considerado como a mais importante política do Governo Federal voltada para o desenvolvimento de políticas próprias de educação em tempo integral, por parte das instâncias subnacionais (BRASIL, 2013).

A educação em tempo integral conquistou status de meta específica no PNE 2014-2024, devendo atingir, no decênio de vigência do referido Plano, "no mínimo, $50 \%$ (cinquenta por cento) das escolas públicas", bem como atender, pelo menos, " $25 \%$ (vinte e cinco por cento) dos(as) alunos(as) da educação básica" (BRASIL, 2014, Meta 6). Não foi por mero acaso que a sequência das metas do principal instrumento de planejamento da educação nacional foi organizada de tal forma que a meta que trata da educação em tempo integral anteceda aquela que aborda a qualidade da educação básica, a Meta 7. Considerada estratégica para o avanço da aprendizagem de crianças e jovens em situação de desvantagem econômica e/ou de vulnerabilidade social, a educação em tempo integral é apresentada, no PNE vigente, como uma alternativa voltada para o enfrentamento das desigualdades educacionais, as quais, na compreensão

${ }^{9}$ No ano de 2013, o PME atingiu 4.836 (86,8\%) dos 5.570 municípios brasileiros (BRASIL, 2013).

RPGE - Revista on line de Política e Gestão Educacional, Araraquara, v. 22, n. esp.1, p. 137-158, mar., 2018. 
do Governo Federal, são passíveis de mensuração por meio do Índice de Desenvolvimento da Educação Básica (Ideb).

\section{Gestão democrática da educação}

Assim como a educação em tempo integral, a gestão democrática da educação vem conquistando significativo espaço nas agendas das políticas educacionais. A preocupação para com sua efetivação revela-se quando, por exemplo, o PNE 20142024, além de estabelecer como diretriz a "promoção do princípio da gestão democrática da educação pública" (BRASIL, 2014), a vincula a uma meta específica, que estabelece que essa gestão seja assegurada de forma "associada a critérios técnicos de mérito e desempenho e à consulta pública à comunidade escolar" (BRASIL, 2014, Meta 19). O Plano determina, ainda, que as instâncias subnacionais aprovem "leis específicas para os seus sistemas de ensino, disciplinando a gestão democrática da educação pública nos respectivos âmbitos de atuação" (BRASIL, 2014). A aprovação das referidas leis específicas, por parte dos entes federados, revela sua premência, entre outros motivos, pelo fato de que a União deverá priorizar o repasse de transferências voluntárias ${ }^{10}$ vinculadas à área da educação para estados e municípios que tenham aprovado legislação "que considere, conjuntamente, para a nomeação dos diretores e diretoras de escola, critérios técnicos de mérito e desempenho, bem como a participação da comunidade escolar" (BRASIL, 2014).

Acompanhada por movimentos no ordenamento normativo ${ }^{11}$, a gestão da educação em nosso país vem, progressivamente, passando por transformações marcadas, dentre outras características, por processos de descentralização, pela busca da participação da comunidade escolar nos processos decisórios, bem como pela transferência de responsabilidades, envolvendo, por vezes, atores sociais diversos no compartilhamento das ações da escola (OLIVEIRA, 2014). Sob essa perspectiva, a escola deixa de deter a responsabilidade exclusiva para com a educação dos alunos e

${ }^{10}$ De acordo com o glossário associado ao Orçamento da União, disposto na página do Senado Federal, "Compreende a entrega de recursos correntes ou de capital a outro ente da Federação, a título de cooperação, auxílio ou assistência financeira, que não decorra de determinação constitucional ou legal ou se destine ao Sistema Único de Saúde". Disponível em: <https://www12.senado.leg.br/orcamento/glossario/transferencias-voluntarias>. Acesso em: 02 out. 2017. ${ }^{11} \mathrm{O}$ ordenamento normativo associado à gestão democrática da educação tem como marco fundante a Constituição Federal de 1988 (BRASIL, 1988).

RPGE - Revista on line de Política e Gestão Educacional, Araraquara, v. 22, n. esp.1, p. 137-158, mar., 2018. 
passa a ser desafiada a compartilhar a tarefa de educar com outras instâncias e atores (MOLL, 2012).

Alinhadas a essa lógica de caráter global, as políticas educacionais com origem no Ministério da Educação, ancoradas no binômio da inclusão-democratização, vêm se articulando, especialmente, por meio das estratégias da territorialidade e da intersetorialidade (DINIZ JUNIOR, 2016), estimulando a participação de diferentes atores sociais na gestão da escola, a qual vem abarcando, para além da sua comunidade, por exemplo, organizações não governamentais, igrejas e empresas, que passam a estabelecer uma relação de parceiros com a unidade de ensino.

Nesse contexto, as mudanças de paradigmas na gestão da educação vêm sendo marcadas por uma forte tendência à adoção de "concepções e práticas interativas, participativas e democráticas" (LÜCK, 2000, p. 12), específicas dos movimentos dinâmicos e globais, com os quais dirigentes, funcionários, "clientes" e "usuários", por meio de redes e parcerias, interagem para determinar as características de produtos e serviços, com vistas a solucionar problemas e ampliar seus horizontes. Tais mudanças, embora acentuadas nos últimos tempos, há muitos anos, vêm impondo "grandes desafios aos gestores escolares, exigindo destes, novas atenções, conhecimentos e habilidades para lidar com as diversidades de demandas sociais, em que a escola vem sendo bombardeada" (LÜCK, 2000, p. 12). A escola de tempo integral tem-se tornado espaço privilegiado para a emergência desses desafios.

\section{A participação nos contextos da gestão democrática e do tempo integral na educação}

A educação integral apresenta relação inequívoca com a gestão democrática. A participação, com a descentralização, a autonomia e a transparência, constitui-se elemento basilar da gestão democrática (BRASIL, 2015; LÜCK, 2009).

No âmbito educacional, a gestão democrática tem sido defendida como estratégia que visa garantir processos coletivos de participação e decisão. Nessa perspectiva, a escola democrática é compreendida como aquela que, dentre outros aspectos, "consegue organizar-se de modo que estimule a participação de todos os implicados" (ROVIRA, 2000 apud VELOSO; CRAVEIRO; RUFINO, 2012, p. 819). De forma mais específica, a gestão democrática na escola desenvolve-se por meio da participação comprometida de todos os seus segmentos, bem como a partir da criação de 
espaços de diálogos e discussões coletivos, implicando o desenvolvimento de uma cultura de troca, reciprocidade e compartilhamento de responsabilidades (LÜCK, 2006).

É necessário, pois, criar condições concretas para se efetivar a democratização da escola, fundamentada, especialmente, na participação de todos os segmentos da comunidade escolar "nos processos de tomada e execução das decisões e a existência de um amplo processo de informação, em que todos tenham conhecimento do que acontece no interior da instituição e suas relações externas" (HORA, 2007, p. 21).

Não obstante, destaca-se que a democratização da educação não se faz associar exclusivamente à democratização da gestão. É essencial que o processo educacional e o espaço escolar se sobressaiam pela qualidade, de modo que todos aqueles que almejam a educação desenvolvam os conhecimentos, as habilidades e as atitudes necessárias "para que possam participar, de modo efetivo e consciente, da construção do tecido da sociedade, com qualidade de vida e desenvolvendo condições para o exercício da cidadania" (LÜCK, 2006, p. 26-7). Sob essa perspectiva, faz-se importante que a escola desenvolva um ambiente favorável à participação de todos os seus segmentos, possibilitando-lhes desenvolver sua "consciência social crítica e sentido de cidadania, condições necessárias para que a gestão escolar democrática e práticas escolares sejam efetivas na promoção da formação de seus alunos" (LÜCK, 2006, p. 78).

Por esse ângulo, pensar a gestão democrática enseja também refletir sobre a formação integral do indivíduo e sobre a necessidade de se construir condições que estabeleçam um "convívio intenso, autêntico e criativo entre todos os elementos da comunidade escolar. Ou seja, é preciso que a escola seja um ambiente onde crianças e adultos vivenciem experiências democráticas" (CAVALIERE, 2002, p. 267).

O PME, ao menos em nível documental, revelava a intenção de ir ao encontro dessas proposições ao recomendar que suas ações e decisões se constituíssem resultado da participação dos diferentes segmentos da comunidade escolar. Para o Programa: "O ideal da Educação Integral traduz a compreensão do direito de aprender como inerente ao direito à vida, à saúde, à liberdade, ao respeito, à dignidade e à convivência familiar e comunitária e como condição para o próprio desenvolvimento de uma sociedade republicana e democrática" (BRASIL, 2011, p. 7).

\section{A participação no contexto da prática do Programa Mais Educação}


Conforme evidenciado anteriormente, foram identificadas três categorias de análise associadas à participação, no contexto da implantação do PME em uma escola integrante da rede municipal de Belém/PA, as quais estão relacionadas: ao processo de adesão da escola ao Programa, à escolha dos macrocampos/oficinas e aos critérios de seleção dos alunos e dos monitores.

Todavia, antes de abordar as referidas categorias, tendo em vista que este trabalho toma por referência um estudo de caso, atenta-se, pontualmente, para a polêmica questão da generalização ${ }^{12}$ para outras realidades dos resultados das pesquisas de cunho prioritariamente qualitativo. Embora a tendência da pesquisa qualitativa seja a da não generalização - haja vista o abarcamento de poucos casos ou caso único, bem como a localização do centro de suas técnicas no entendimento de que "cada pesquisa é única como também o são seus resultados" (SOUSA et al., 2017, p. 476) -, ela torna-se possível a partir de uma ampla compreensão das possibilidades e dos limites de sua utilização. Nesse sentido, ainda a respeito da possibilidade de generalização, os autores apresentam que:

[...] se existe uma realidade local e outras realidades locais que já foram estudadas dentro do mesmo prisma, pode-se recorrer a comparações para evidenciar que existe um processo onde pode ser possível ou não generalizar, como também delimitar os limites da generalização. (SOUSA et al, 2017, p. 472).

Nessa mesma direção, Ward-Schofield (1993 citado por RICHARDSON, 1999, p. 101) sugere que a pesquisa qualitativa pode ser generalizada apenas para "exemplos semelhantes".

Apresentadas essas considerações, passa-se, agora, para a discussão dos resultados das categorias que emergiram da pesquisa.

\section{A participação na adesão ao Programa Mais Educação}

Partindo da compreensão de que o "resultado esperado [da participação] é o envolvimento de toda a comunidade, em especial dos estudantes, em um ambiente favorável à aprendizagem" (BRASIL, 2011, p. 16), observa-se que as discussões relativas à adesão ao PME, por parte da escola pesquisada, se deram no âmbito restrito

12 A generalização consiste na "inferência de qualidade, de casos singulares ou de unidades de análise circunscrita, para outros casos, unidades ou conjunto deles, sendo que os mesmos não foram objetos de observação e análise" (SOUZA; LIMA, 2011 apud SOUSA et al, 2017, p. 472).

RPGE - Revista on line de Política e Gestão Educacional, Araraquara, v. 22, n. esp.1, p. 137-158, mar., 2018. 
da Secretaria Municipal de Educação (Semec), em conjunto com a diretora da escola e sua equipe pedagógica, não contando, portanto, com a participação dos diferentes segmentos da comunidade escolar e não atendendo, dessa forma, às determinações presentes nos documentos orientadores do Programa, anteriormente destacados.

De acordo com a coordenadora do PME na escola: "[...] foi assim: a Semec nos chamou, pediu para que fossemos a algumas reuniões, e fizemos a adesão ao Programa, que nós achamos bom para a escola". Essa afirmação foi corroborada pela diretora quando evidenciou que: “[...] fizemos isso [a adesão ao PME] lá na secretaria [Semec], porque não tínhamos computador com internet na época. Eles [a secretaria] nos instruíram".

Logo, a opção pela adesão ao Programa, realizada no ano de 2010, deu-se sob a orientação da Secretaria de Educação, a qual foi motivada, especialmente, pelo repasse adicional de verbas, que, no seu entendimento, viria a contribuir para a melhoria do ensino nas escolas municipais beneficiadas. Mais especificamente, segundo o coordenador municipal do PME, "o motivo da Semec aderir ao PME foi que o MEC ofereceu a possibilidade de um Programa que pudesse trazer recursos para as escolas e poder melhorar a qualidade de aprendizagem do aluno”. Essa justificativa para adesão ao PME - que conjuga, embora dentre outros fatores, porém especialmente, a conquista de recursos $^{13}$ ao avanço da qualidade na educação - não se constitui exclusividade da escola pesquisada, haja vista a sua apresentação em significativo número de pesquisas realizadas no país (BRASIL, 2013; MARTINS, 2016; MENEZES, 2011; MENEZES, PAIVA; OLIVEIRA, 2017; MOSNA, 2014).

De acordo com a coordenadora do PME na escola, as dificuldades para que fossem promovidas discussões com a comunidade escolar deveram-se, especialmente, aos limites exíguos dos prazos fixados pelo Governo Federal para que fosse efetivada a adesão ao Programa. A assinatura de convênios/acordos/compromissos inerentes à implantação de políticas de educação provenientes da administração federal, as quais se associam à disponibilidade de assistência técnica e financeira ${ }^{14}$, não raro, não oferece prazos adequados para que as secretarias de educação de estados, municípios e do

13 As matrículas correspondentes aos alunos inscritos no PME - afora fazerem jus aos recursos do Fundeb, com um acréscimo de até $30 \%$ de recursos comparativamente às matrículas do ensino fundamental urbano - recebiam do Fundo Nacional de Desenvolvimento da Educação (FNDE), na condição de assistência financeira, recursos adicionais advindos do "Programa Dinheiro Direto na Escola - PDDE e do Programa Nacional de Alimentação Escolar - PNAE, instituído pela Lei no ${ }^{\circ} 11.947$, de 16 de junho de 2009" (BRASIL, 2010).

${ }^{14}$ A assistência técnica e financeira está disposta na Constituição Federal de 1988, com redação dada pela Emenda Constitucional 14 (BRASIL, 1988), conferir em Souza e Menezes (2015).

RPGE - Revista on line de Política e Gestão Educacional, Araraquara, v. 22, n. esp.1, p. 137-158, mar., 2018. 
Distrito Federal e, em especial, as escolas discutam e decidam sobre as propostas que lhes estão sendo disponibilizadas. Tal contexto vem contribuindo para que as escolas implantem programas que acabam sendo recebidos sem a realização de um planejamento prévio e sem o envolvimento da comunidade escolar, já que, em parte significativa das vezes, o foco das discussões associadas à decisão por uma adesão, ou não, a tais programas acaba sendo ofuscado pela possibilidade da conquista de novos recursos (humanos, materiais, técnicos e, especialmente, financeiros), envolvendo apenas alguns profissionais nos processos decisórios.

A realidade das condições infraestruturais ${ }^{15}$ das escolas de nosso país - cita-se o fato de a escola, aqui analisada, não contar com internet, dentre outras tantas demandas a serem atendidas - constitui-se um dos fatores que contribui para o elevado grau de dependência das escolas em relação às decisões da Secretaria de Educação. Esta, por sua vez, em geral, apresenta uma realidade assentada na dependência do apoio técnico e financeiro oriundo do Governo Federal, disponibilizado, de forma precária, a partir da adesão a políticas indutoras. Tal conjuntura colabora para o estabelecimento de uma dependência verticalizada, permeada pela subordinação e, por vezes, pela submissão (MACHADO, 1999), afastando a escola de alguns de seus propósitos, dentre eles: o de uma gestão participativa e, concomitantemente, o da perspectiva de uma educação voltada para a formação integral do sujeito. Tal cenário possibilita a emergência da seguinte pergunta: diante do contexto que envolve a educação brasileira, teriam as escolas reais condições de optarem pela não adesão a tais políticas?.

Assim, a partir da constatação da contraposição entre o que apresentam alguns dos documentos orientadores do PME e o processo que envolveu a adesão ao Programa pela escola pesquisada, é possível identificar aí a presença de dois problemas reincidentes nas políticas educacionais brasileiras, quais sejam, a já constatada ausência de uma maior articulação com as escolas e a descontinuidade (FERREIRA, 2012).

A essência da (des)continuidade ${ }^{16}$ consiste em um "eterno recomeçar, como se o passado pudesse ser anulado; a repetição constante do 'novo' para manter as mesmas relações de poder estabelecidas" (COLLARES; MOYSÉS; GERALDI, 1999 apud

15 O PNE 2014-2024, na meta que visa fomentar a qualidade da educação básica, apresenta estratégia direcionada para itens de infraestrutura nas escolas (BRASIL, 2014, Meta 7, Estratégia 7.18). A partir de consulta à plataforma Observatório do PNE (www.observatóriodopne.org.br), que visa possibilitar o acompanhamento do Plano, é possível constatar a precariedade das condições infraestruturais das escolas brasileiras.

${ }^{16}$ A palavra "(des)continuidade" é utilizada para referendar o pensamento de Estevam (2010, p. 2), para o qual "a descontinuidade contém elementos de continuidade e, a continuidade, elementos da descontinuidade".

RPGE - Revista on line de Política e Gestão Educacional, Araraquara, v. 22, n. esp.1, p. 137-158, mar., 2018. 
ESTEVAM, 2010, p. 3). O entendimento da (des)continuidade no âmbito das políticas públicas em educação passa por um momento de inflexão em nosso país, a partir do qual deixa de ser percebida como inerente a tais políticas para ser compreendida como política $^{17}$. Sob essa perspectiva, a (des)continuidade deixa de ser considerada como uma característica prevista das referidas políticas para ser compreendida como ação intencional e sistemática, direcionada a setores específicos da população e levada a cabo, de forma consciente, por aqueles que estão à frente ou participam de governos. Dentre tantos possíveis exemplos, apresenta-se a transposição do PME pelo PNME.

Contudo, vale refletir, aqui, sobre a afirmação de Bordenave (1994, p. 78), para o qual "um projeto participativo não se acaba quando se retiram as fontes externas de assistência, pois as pessoas o consideram 'seu'”. Para o autor, a participação possibilita que as pessoas sejam envolvidas pela/na/com política, apropriando-se dela e passando, assim, a se sentirem corresponsáveis pelo seu sucesso ou fracasso.

\section{A participação na escolha dos macrocampos/oficinas do Programa Mais Educação}

A participação na escolha, junto ao Sistema Integrado de Monitoramento, Execução e Controle (Simec) ${ }^{18}$, dos macrocampos/oficinas ${ }^{19}$ do PME que deveriam ser oferecidas pela escola, também ocorreu de forma restrita, envolvendo apenas a diretora e sua equipe pedagógica, bem como a coordenadora institucional do programa. A esse respeito, os depoimentos das referidas coordenadora e diretora se complementaram na medida em que a primeira evidenciou que "a Semec convoca para uma reunião e avisa que o Simec vai abrir para a escola escolher as oficinas do PME", e a segunda afirmou que "Uma equipe da escola foi lá [na Semec] escolher as oficinas que tinham mais a ver com o projeto político pedagógico".

Mesmo buscando ir ao encontro do projeto pedagógico da escola, tal qual determinam os dois principais ordenamentos do $\mathrm{PME}^{20}$, o procedimento de relacionar a

${ }^{17}$ Essa reflexão teve origem em uma palestra do professor Luiz Fernandes Dourado, proferida na Unirio, no dia 01/09/2017.

${ }^{18}$ Até 2013, o cadastro das escolas no PME se dava por meio do Simec. A partir daquele ano, o MEC passou a utilizar sistema Programa Dinheiro Direto na Escola Interativo (PDDE Interativo).

${ }^{19}$ As atividades PME foram organizadas em macrocampos, os quais, em 2014, estavam divididos em: Acompanhamento Pedagógico; Comunicação e uso de Mídias; Cultura Digital e Tecnológica; Cultura, Arte e Educação Patrimonial; Educação Ambiental; Esporte e Lazer; Educação em Direitos Humanos; e Promoção da Saúde (BRASIL, 2014a). No período de vigência do PME, os macrocampos e suas respectivas oficinas passaram por alterações tanto no que tange à sua definição quanto no que se refere ao número disponibilizado para cada escola.

${ }^{20}$ Portaria Interministerial 17/2007 (BRASIL, 2007) e o Decreto $n^{\circ}$ 7.083/2010 (BRASIL, 2010).

RPGE - Revista on line de Política e Gestão Educacional, Araraquara, v. 22, n. esp.1, p. 137-158, mar., 2018. 
definição dos macrocampos/oficinas do Programa a apenas alguns profissionais vinculados à escola foi sendo renovado a cada ano, excluindo de tal decisão a participação de pais, alunos, professores e outros integrantes da comunidade escolar.

Quando questionada sobre a participação da comunidade escolar na escolha dos macrocampos/oficinas do Mais Educação, a mãe de um aluno, a exemplo de outros pais/responsáveis, relatou que soube do PME e de suas oficinas por meio do filho: "Eu trabalho, quando ele me falou, procurei a escola, porque ele estava interessado".

A participação dos pais/responsáveis limitou-se à sua presença na escola para receber informações e/ou para efetivar a inscrição de seu(s) filho(s) no Programa e, por conseguinte, em suas oficinas. Quando analisada à luz dos estudos de Bordenave (1994), a participação dos pais/responsáveis, no contexto do PME, associa-se à classificação de menor grau, qual seja, aquela que se dá apenas no âmbito da informação ${ }^{21}$. Nesse caso, os pais são apenas informados "sobre as decisões já tomadas" (BORDENAVE, 1994, p. 31), sendo que as possíveis reações a essas informações, algumas vezes, são consideradas pela escola, levando-a a reorientar a decisão inicial. A adoção desse grau de participação firma-se na posição diametralmente oposta àquela que busca "o crescimento da consciência crítica da população" com vistas a fortalecer "seu poder de reivindicação" e prepará-la "para adquirir mais poder na sociedade" (BORDENAVE, 1994, p. 12).

Já a participação dos alunos no processo de seleção dos macrocampos/oficinas do PME deveria ter ocorrido em duas etapas sequenciais: a primeira, conforme já apresentado, relaciona-se à definição, no âmbito do Simec, dos macrocampos/oficinas que viriam a ser implantados na escola; e a segunda associa-se à escolha, por parte daqueles já inscritos no PME, das oficinas que pretendiam frequentar. Embora os alunos não tenham opinado sobre os macrocampos/oficinas selecionados por sua escola, dentre as oficinas implantadas, foram consultados sobre aquelas que gostariam de frequentar. Perguntados sobre esse segundo momento, um dos alunos respondeu: "Sim, eu escolhi as oficinas de futsal e grafite", já outro aluno evidenciou: “[na verdade] não tive opção de escolha". A última resposta deveu-se ao fato de a inscrição no Programa estar associada, concomitantemente, à obrigatoriedade de inscrição em um número estabelecido de oficinas definidas, previamente, por um processo que não contou com a

${ }^{21} \mathrm{O}$ autor define sete graus de participação, apresentados em uma progressão crescente: informação/reação, consulta facultativa, consulta obrigatória, elaboração/recomendação, cogestão, delegação e autogestão, em que o maior grau corresponde à cogestão, e esta é "compartilhada mediante mecanismos de codecisão e colegialidade" (BORDENAVE, 1994, p. 32). 
participação dos alunos, as quais, no caso da realidade específica do entrevistado, não foram ao encontro de suas inquietações e interesses. Constata-se, assim, que a restrição à participação dos alunos também integra um conjunto verticalizado de decisões: se, por um lado, a escola foi compelida a definir, dentro de um conjunto pré-definido pelo MEC, os macrocampos/oficinas que viria a implantar, por outro, os alunos viram-se na contingência de escolher, dentro de um conjunto pré-definido por sua escola, as oficinas que viriam a frequentar.

No contexto dos resultados apresentados, resgata-se o pensamento de Dewey (apud APPLE; BEANE, 1997, p. 17) quando observa que: “[...] se as pessoas quiserem assegurar e manter um modo de vida democrático, precisam de oportunidades para descobrir o que significa esse modo de vida e como pode ser vivenciado". Esse modo de vida é fundamental "para pensarmos em escolas democráticas, com práticas de democracia situadas na convivialidade humana, entre docentes e discentes, na comunidade escolar" (SILVA; BUSNELLO; PEZENATTO, 2014, p. 403).

É importante destacar, aqui, que "a gestão democrática deve estar impregnada por uma certa atmosfera que se respira na escola" (GADOTTI, [2017], p. 3, grifo do autor), envolvendo, indiscriminadamente, todas as suas ações. Para o autor, a gestão democrática é "atitude e método. A atitude democrática é necessária, mas não é suficiente. Precisamos de métodos democráticos de efetivo exercício da democracia. Ela também é um aprendizado, demanda tempo, atenção e trabalho" (GADOTTI, [2017], p. 3 , grifos do autor).

\section{A participação nos critérios de seleção dos alunos e dos monitores para o Programa Mais Educação}

A participação na definição dos "critérios de seleção dos alunos para o PME" decorreu especialmente de reuniões promovidas com os professores regentes, pais e a equipe pedagógica, nas quais os critérios estabelecidos corresponderam, na prática, àqueles determinados pelo MEC em alguns de seus documentos orientadores ${ }^{22}$, apresentando, porém, certa flexibilidade.

De acordo com a coordenadora do PME na escola, "todo aluno é bem-vindo ao Programa”. Segundo ela, os critérios associados à seleção dos estudantes priorizavam aqueles que apresentavam problemas de aprendizagem e/ou vulnerabilidade social,

22 Destacam-se, aqui, os manuais operacionais de educação integral, publicados anualmente, no período de 2008 a 2014, e elencados por Diniz Júnior (2016).

RPGE - Revista on line de Política e Gestão Educacional, Araraquara, v. 22, n. esp.1, p. 137-158, mar., 2018. 
sendo que, na medida da disponibilidade de vagas, a escola também possibilitava a inscrição de alunos que não se encaixavam nessas duas orientações prioritárias. Ao oportunizar também a participação de alunos que procuravam o PME, além de a escola atender às orientações do Programa - o qual, por exemplo, determinava que: "Cada escola, contextualizada com seu projeto político pedagógico específico e em diálogo com sua comunidade, será a referência para se definir quantos e quais alunos participarão das atividades" (BRASIL, 2011, p. 13) -, buscava evitar que se formassem preconceitos e/ou rótulos associados aos inscritos, que poderiam, por conseguinte, estigmatizá-los.

Ao tratar dos alunos que poderiam ser inscritos no PME, o documento acima citado também apresenta que é "desejável que o conjunto da escola participe nas escolhas" (BRASIL, 2011, p. 13), apontando, embora de forma subliminar, para a importância da participação nos processos decisórios vinculados ao Programa.

Já a participação na definição dos "critérios de seleção dos monitores ${ }^{23}$ do PME" buscou atender a critérios definidos pelo MEC e pela Semec, em que a seleção desses novos educadores ${ }^{24}$ ficou centrada na coordenação do Programa na escola. Nesse sentido, a coordenadora pedagógica relatou que: "Ela [a coordenadora do PME na escola] é que seleciona. Nós não fazemos parte dessa seleção. Sei é que é através de currículos, que são analisados por ela, e de uma entrevista, em que pede um projeto dentro daquela oficina que será desenvolvida". A esse respeito, a coordenadora do PME na escola relatou que, além de buscar atender às determinações do Programa - que especificava que, preferencialmente, fossem selecionados estudantes universitários ou pessoas da comunidade com habilidades nas áreas que pretendiam atuar (BRASIL, 2013) -, solicitava que os candidatos a monitores apresentassem e defendessem um projeto vinculado às atividades que pretendiam desenvolver na oficina para a qual estavam se candidatando, avançando, assim, para além das orientações do PME.

A coordenadora do PME também destacou a importância, para a escola, de os monitores, quando estudantes universitários, terem levado o debate sobre o PME para as instituições de ensino superior onde estavam matriculados. Além de expressar um possível diálogo, intermediado pelo monitor, da escola com a universidade, tal afirmação também possibilita inferir que a estratégia de priorizar a seleção de estudantes

${ }^{23}$ A atuação dos monitores dá-se por meio do serviço voluntário, amparado pela Lei ${ }^{\circ}$ 9.608/1988 (BRASIL, 1988a).

${ }^{24}$ Para Oliveira (2014), essa nomenclatura inclui, além daqueles comumente incluídos na categoria "profissionais da educação", os monitores/“oficineiros" que atuam nas escolas de tempo integral.

RPGE - Revista on line de Política e Gestão Educacional, Araraquara, v. 22, n. esp.1, p. 137-158, mar., 2018. 
universitários para atuarem como monitores do PME nas escolas fomentou discussões associadas ao Programa - e quiçá, de modo mais geral, relacionadas ao campo das políticas públicas de educação integral $\mathrm{e}(\mathrm{m})$ tempo integral - nas instituições de formação desses sujeitos, ampliando o processo de participação nas referidas discussões para além das escolas e das redes públicas de educação básica que o implantaram. Mamede (2012, p. 243), ao analisar o papel das universidades no contexto da formação em educação integral e partindo da constatação de que o PME se apresentava como o "formato mais presente nos municípios brasileiros", destaca que reside na perspectiva da atuação para a educação integral "um dos mais frutíferos canais para a participação da universidade como agência formadora".

Contudo, diferentemente da pesquisada, a imensa maioria das escolas do país não conta com a possibilidade de estabelecer uma interlocução indireta com as universidades, a partir da atuação de seus estudantes de graduação como monitores no Programa. O tema é controverso, pois envolve a admissão no ambiente escolar, por parte das instâncias subnacionais, de monitores, por vezes, sem formação pedagógica e/ou sem formação específica para a oficina que se propõem desenvolver, carecendo, pois, de especial atenção por parte do processo de monitoramento e avaliação dessa política pública.

Após discutir a participação nos processos de decisão que envolviam a adesão, a escolha dos macrocampos/oficinas e a definição dos critérios de seleção dos alunos e dos monitores do PME, julga-se necessário apresentar, ainda, como passou a se dar o diálogo do Programa com a comunidade escolar, no cotidiano de sua implementação. Quando questionada sobre o tema, a coordenadora do PME na escola observou que: "Nós temos feito todo um trabalho de divulgação: vamos às salas, falamos da importância; nas reuniões sempre apresentamos o Programa para os pais, dizendo que é uma oportunidade".

Assim, sem desconsiderar o valor das ações da escola, um último aspecto a ser destacado refere-se à interpretação do sentido da participação que considera a abertura de espaços nas reuniões escolares para a expressão de opiniões, ideias, pontos de vista, informes e referendos de decisões já tomadas pela escola como principal evidência de um espaço democrático de participação. Essa prática, denominada por Lück (2006, p. 39-40) de "participação como expressão verbal e discussão de ideias", embora ofereça às pessoas a liberdade de uso da expressão, pode não possibilitar mais do que uma simples verbalização, que não promove avanços nos processos de tomadas de decisões 
compartilhadas, não se constituindo, sob essa perspectiva, em um exercício de democracia.

\section{Considerações finais}

A implantação do PME, em âmbito nacional, tanto reanimou como também apensou novas questões a antigas inquietações e polêmicas que ainda aguardam por melhores encaminhamentos no contexto educacional brasileiro, a citar, não só as questões inerentes à participação sob o prisma da gestão democrática, mas também ao currículo, ao financiamento da educação, à infraestrutura das escolas e à formação dos educadores.

Criado no âmbito do executivo federal, com vistas à ampliação da jornada escolar na perspectiva da educação integral (BRASIL, 2007, 2010, 2011), o PME impactou diretamente a gestão da escola, alterando sua dinâmica cotidiana, tornando-a mais complexa e trazendo consigo antigos e novos desafios à responsabilidade da comunidade escolar e, de modo particular, de seus gestores.

Embora conte com documentos elaborados pelo MEC, que valorizam e estimulam a participação da comunidade escolar na perspectiva da gestão democrática, na prática, mesmo sendo possível perceber avanços nessa direção, a participação no PME revela-se restrita a alguns de seus integrantes, especialmente àqueles que atuam na administração das escolas. Esse é o caso da escola pesquisada.

A partir desse contexto, observa-se que "qualquer processo que estimule o aprendizado, a vivência da participação e da democracia é essencial para a construção de uma nova forma de gestão dos interesses de indivíduos, grupos, categorias ou classes sociais" (HELO, 2011, p. 105). É a partir da plena participação de seus sujeitos que a escola se torna um espaço de aprendizagem da democracia, cujos integrantes, conscientes do seu papel social e imersos em uma cultura de poder compartilhado, contribuem para a construção de sua "autonomia e empoderamento pelo alargamento da consciência social e desenvolvimento de competências sociais" (LÜCK, 2006, p. 66).

A participação constitui-se um dos alicerces para a democratização da escola e, consequentemente, para a democratização de seus processos sociais. Busca estabelecer, nas instituições, "ambientes e práticas educacionais caracterizados pela construção da autonomia, da responsabilidade social e da cidadania, que se constituem, por sua vez, em condição fundamental para a adequada formação humano-social” (LÜCK, 2009, p. 
20). Tal ambiência faz-se necessária para o desenvolvimento de políticas que, tais como o PME, busca(va)m “induzir a ampliação da jornada escolar e a organização curricular, na perspectiva da educação integral" (BRASIL, 2011, p. 7). Nesse sentido, observa-se, por fim, que a participação é "uma necessidade humana e, por conseguinte, constitui-se em direito das pessoas. [...] Privar os homens de satisfazerem estas necessidades equivale a mutilar o desenvolvimento harmônico de sua personalidade integral" (BORDENAVE, 1994, p. 77, grifos nossos).

\section{REFERÊNCIAS}

APPLE, M. e BEANE, J. Escolas democráticas. São Paulo: Cortez, 1997.

BALL, S. J.; BOWE, R. Subject departments and the 'implementation' of National Curriculum policy: an overview of the issues. Journal of Curriculum Studies, v. 24, n. 2, p. 97-115, 1992.

BARDIN, L. Análise de conteúdo. Lisboa, Portugal: Edições 70, 1977.

BORDENAVE, J. E. D. O que é participação? São Paulo, Brasiliense, 1994. (Coleção Primeiros Passos).

BRASIL. Constituição da República Federativa do Brasil. Brasília, DF: Senado Federal: Centro Gráfico, 1988.

BRASIL. Lei n ${ }^{\circ} 9.608$, de 18 de fevereiro de 1988. Dispõe sobre o serviço voluntário e dá outras providências. Diário Oficial da União [da] República Federativa do Brasil, Brasília, DF, 19 fev. 1988a.

BRASIL. Lei no 9.394, de 20 de dezembro de 1996. Estabelece as Diretrizes e Bases da Educação Nacional. Diário Oficial da União [da] República Federativa do Brasil, Brasília, DF, 23 dez. 1996.

BRASIL. Lei $n^{\circ}$ 10.172, de 09 de janeiro de 2001. Aprova o Plano Nacional de Educação (PNE). Diário Oficial da União [da] República Federativa do Brasil, Brasília, DF, 10 jan. 2001.

BRASIL. Lei n ${ }^{\circ} 11.494$, de 20 de junho de 2007. Regulamenta o Fundo de Manutenção e Desenvolvimento da Educação Básica e de Valorização dos Profissionais da Educação - FUNDEB, de que trata o art. 60 do Ato das Disposições Constitucionais Transitórias; altera a Lei $\mathrm{n}$ - 10.195 , de 14 de fevereiro de 2001; revoga dispositivos das Leis n os 9.424, de 24 de dezembro de 1996, 10.880, de 9 de junho de 2004, e 10.845, de 5 de março de 2004; e dá outras providências. Diário Oficial da União [da] República Federativa do Brasil, Brasília, DF, 21 jun. 2007.

BRASIL. Portaria Interministerial no 17 de 24 de abril de 2007. Programa Mais Educação. Brasília, DF. 2007.

RPGE - Revista on line de Política e Gestão Educacional, Araraquara, v. 22, n. esp.1, p. 137-158, mar., 2018. 
BRASIL. Ministério da Educação. Secretaria de Educação Básica. Diretoria de Currículo e Educação Integral. Educação integral/educação integrada e(m) tempo integral: concepções e práticas na educação brasileira (Mapeamento das experiências de jornada escolar ampliada no Brasil). Brasília, 2009. Disponível em:

<http://portal.mec.gov.br/docman/junho-2011-pdf/8198-8-1-mais-educacao-relatoriofinal-maio-2011-pesq-quanti-seb-pdf/file>. Acesso em: 20 set. 2017.

BRASIL. Decreto $n^{\circ} 7.083$, de 27 de janeiro de 2010. Dispõe sobre o Programa Mais Educação. Diário Oficial da União [da] República Federativa do Brasil, Brasília, DF, 27 jan. 2010.

BRASIL. Ministério da Educação. Programa Mais Educação: manual passo-a-passo. Brasília, DF: MEC, 2011.

BRASIL. Ministério da Educação. Secretaria de Educação Básica. Diretoria de Currículo e Educação Integral. Programa Mais Educação: Impactos na Educação Integral e Integrada. Brasília, 2013. Disponível em:

<http://educacaointegral.mec.gov.br/images/pdf/pesquisa_ufmg_relatorio_final.pdf>. Acesso em: 20 set. 2017.

BRASIL. Lei n ${ }^{\circ} 13.005$, de 25 de junho de 2014. Aprova o Plano Nacional de Educação - PNE e dá outras providências. Diário Oficial da União [da] República Federativa do Brasil, Brasília, DF, 26 jun. 2014.

BRASIL. Ministério da Educação (MEC). Secretaria de Educação Básica (SEB). Manual de Educação Integral para obtenção de apoio financeiro através do Programa Dinheiro Direto na Escola: PDDE/integral, no exercício de 2014. Brasília, DF, 2014a.

BRASIL. Portaria $n^{\circ} 1.144$, de 10 de outubro de 2016. Institui o Programa Novo Mais Educação, que visa melhorar a aprendizagem em língua portuguesa e matemática no ensino fundamental. Diário Oficial da União [da] República Federativa do Brasil, Brasília, DF, 11 out. 2016.

BRASIL, R. S. O Programa Mais Educação e a gestão democrática: a experiência de uma escola municipal em Belém/PA. 2015. 185f. Dissertação (Mestrado em Educação) - Universidade Federal do Estado do Rio de Janeiro, Rio de Janeiro, 2015.

CAVALIERE, A. M. V. Educação integral: uma nova identidade para a escola brasileira. Educação e Sociedade. Campinas: CEDES, v. 23, n. 81, p. 247-271, dez. 2002.

DINIZ JUNIOR, C. A. Comitês territoriais de Educação Integral: das ideias ao texto. 2016. 143f. Dissertação (Mestrado em Educação) - Universidade Federal do Estado do Rio de Janeiro, Rio de Janeiro, 2016.

ESTEVAM, D. O. A contínua descontinuidade administrativa e de políticas públicas. Seminário de Ciências Sociais Aplicadas. Santa Catarina, Unesc, 2010. Disponível 
em: <http://periodicos.unesc.net/seminariocsa/article/view/1390/0>. Acesso em: 10 set. 2017.

FERREIRA, C. G. O Programa Mais Educação na perspectiva da gestão escolar: a dinâmica da tomada de decisão e a gestão participativa. 2012. 137f. Dissertação (Mestrado em Educação) - Universidade do Estado da Bahia, Salvador, 2012.

GADOTTI, M. O projeto político-pedagógico da escola na perspectiva de uma educação para a cidadania. [s.a]. Disponível em:

<http://files.professorivo.webnode.pt/200000095-f1511f24b6/PPP\%20-

$\%$ 20Moacir\%20Gadotti.pdf>. Acesso em: 10 set. 2017.

HELO, L. B. Conselhos Escolares: a possibilidade do exercício da democracia. In: PERONI V. M. V.; ROSSI, A. J. (Org.). Políticas educacionais em tempos de redefinições no papel do Estado: implicações para a democratização da educação, Porto Alegre: Programa de Pós-Graduação em Educação da UFRGS. Gráfica e Editora UFPEL, 2011.

HORA, D. L. Gestão democrática na escola. Campinas: Alínea, 2007.

LÜCK, H. Texto Apresentação. Conselho Nacional de Secretários de Educação (CONSED) e Centro de Desenvolvimento Humano Aplicado (CEDHAP). In: Em Aberto, Brasília, v. 17, n. 72, p. 7-10, fev./jun. 2000.

LÜCK, H. A gestão participativa na escola. Petrópolis, RJ: Vozes, 2006.

LÜCK, H. Concepções e processos democráticos de gestão educacional. Petrópolis, RJ: Vozes, 2009.

MACHADO, L. T. A teoria da dependência na América Latina. Estudos Avançados, São Paulo, v. 13, n. 35, 1999.

MAINARDES, J. Abordagem do ciclo de políticas: uma contribuição para a análise de políticas educacionais. Educação \& Sociedade, Campinas, v. 27, n. 94, p. 47-69, jan./abr., 2006.

MARTINS, E. C. A contextualização do Programa Mais Educação em escolas do município de Ponta Grossa/PG: desafios e perspectivas da gestão escolar. Dissertação (Mestrado em Educação) - Universidade Estadual do Centro-Oeste, 2016.

MAMEDE, I. C. M. A Integração da universidade para a formação em educação integral: muitos desafios, várias possibilidades. In: MOLL, Jaqueline e colaboradores (Org.). Caminhos da educação integral no Brasil: direito a outros tempos e espaços educativos. Porto Alegre: Penso, 2012, p. 235-245.

MENEZES, J. S. S. Educação integral e tempo integral na educação básica: da LDB ao PDE. In: Lígia Martha Coimbra da Costa Coelho (Org.). Educação integral em tempo integral: estudos e experiências em processo. Rio de Janeiro: DP et Alii, 2009, p. 6988.

RPGE - Revista on line de Política e Gestão Educacional, Araraquara, v. 22, n. esp.1, p. 137-158, mar., 2018. 
MENEZES, J. S. S. Experiências de jornada escolar ampliada da rede municipal de Natal/RN - Relatório de Pesquisa. Rio de Janeiro, Neephi/Unirio, 2011.

MENEZES, J. S. S; PAIVA, F. R. S; OLIVEIRA, L. G. O Programa Mais Educação e a construção da política pública de educação em tempo integral em Mesquita/RJ. Recife: Fundaj, 2017. (Capítulo de livro no prelo).

MOLL, J. A agenda da educação integral: compromissos para a sua consolidação como política pública. In: MOLL, J. et al. (Org.). Caminhos da educação integral no Brasil: direito a outros tempos e espaços educativos. Porto Alegre: Penso, 2012, p. 129-147.

MOSNA. R. M. P. Avaliação da política pública "Programa Mais Educação" em escolas de ensino fundamental da rede estadual de ensino do Rio Grande do Sul: impactos na qualidade da educação e no financiamento do ensino fundamental. 2014. 249f. Tese (Doutorado em Educação) - Universidade Federal do Rio Grande do Sul, Porto Alegre, 2014.

OLIVEIRA, L. G. A Formação continuada no âmbito do Programa Mais Educação no Município de Mesquita - RJ. 2014. Dissertação (Mestrado em Educação) Universidade Federal do Estado do Rio de Janeiro, Rio de Janeiro, 2014.

PAZETO, A. E. Participação: exigência para a qualificação do gestor e processo permanente de atualização. Em Aberto. v. 17, nº 72, p. 163-166, fev./jun., 2000.

RICHARDSON, J. R. Pesquisa social: métodos e técnicas. São Paulo, Atlas, 1999.

SOUSA, A. J, et al. A generalização dos resultados da pesquisa qualitativa no campo da Administração: reflexão sobre seus limites e possibilidades. Brazilian Journal of Development, Curitiba, v. 3, p. 465-480, dez. 2017.

SOUZA, D. B.; MENEZES, J. S. S. Planos estaduais de educação: (des)vinculações com a gestão dos sistemas estaduais de ensino. In: SOUZA, Donaldo Bello de; DUARTE, Marisa Ribeiro Teixeira; OLIVEIRA, Rosimar de Fátima (Org.). Sistemas educacionais: concepções, tensões, desafios. São Paulo: Loyola, 2015, p. 139-172.

SILVA, R. M. D; BUSNELLO, C.P; PEZENATTO F. Política, cidadania e educação integral: a convivência democrática como princípio pedagógico. RBPAE, Goiás, v. 30, n. 2, p. 397-416, maio/ago., 2014

VELOSO, L; CRAVEIRO, D; RUFINO, I. Participação da comunidade educativa na gestão escolar. Educ. Pesquisa, São Paulo, v. 38, n. 4, p. 815-832, out./dez., 2012.

YIN, R.K. Estudo de caso: planejamento e métodos. Porto Alegre: Bookman, 2005. 


\section{Como referenciar este artigo}

MENEZES, Janaína Specht da Silva.; BRASIL, Rozineide Souza. Gestão democrática na escola: a participação no contexto da prática de um programa de educação em tempo integral. Revista on line de Política e Gestão Educacional, Araraquara, v. 22, n. esp.1, p. 137-158, mar., 2018. E-ISSN:1519-9029.

Submetido em: 04/10/2017

Aprovado em: 14/12/2017 